\title{
Correction to: Factors determining vegetation recovery after abandonment of coal-mining villages
}

\author{
Nanane Motosugi ${ }^{1} \cdot$ Futoshi Nakamura $^{1}$ (D) Souta Nakajima ${ }^{1} \cdot$ Chihiro Takahata $^{1} \cdot$ Kazuhiro Kawamura $^{1}$. \\ Junko Morimoto ${ }^{1}$
}

Published online: 23 February 2021

(c) International Consortium of Landscape and Ecological Engineering 2021

Correction to: Landscape and Ecological Engineering https://doi.org/10.1007/s11355-020-00438-3

In the original publication of the article, the following reference was not included and provided in this correction.

Nakamura F, Ishiyama N, Yamanaka S, Higa M, Akasaka T, Kobayashi Y, Ono S, Fuke N, Kitazawa M, Morimoto J, Shoji Y (2020) Adaptation to climate change and conservation of biodiversity using green infrastructure. River Res Appl 36:921-933

The original article has been updated.

The original article can be found online at https://doi.org/10.1007/ s11355-020-00438-3.

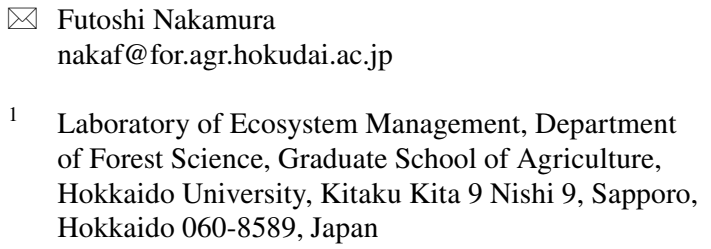

